\title{
Does MBA Studies Increase the Value of Human Capital in the Labour Market?
}

\author{
Kateřina Bočková, Václav Šimek, Michal Hanák \\ DTI University, Sládkovičova 533/20, Dubnica nad Váhom, Slovakia
}

\begin{abstract}
Presented paper focuses on a research of added value of MBA studies organized at Academy of crisis management and management, Ltd. Uherské Hradiště on its graduates. The added value in this research is monitored in correlation to graduates' career, recorded changes and also in correlation to the development of their knowledge and skills. Attention is also devoted to the returns of funds invested in these studies. The data are obtained thanks to a semistructured interview and a questionnaire survey among MBA graduates. They are processed by using mathematical-statistical methods, methods of comparison and analysis of information.
\end{abstract}

Keywords - MBA studies, Master of Business Administration, managerial education, life-long learning, human capital, added value of education, Academy of Crisis Management and Management, Ltd. Uherské Hradiště.

\section{Introduction}

Education is a very important element of today's world. It helps to differentiate individuals from others, and above all it sets the direction of our career, it deepens our knowledge and skills that are needed to enter a desired area in the labour market.

DOI: $10.18421 /$ TEM104-49

https://doi.org/10.18421/TEM104-49

Corresponding author: Kateřina Bočková,

DTI University, Sládkovičova 533/20, Dubnica nad Váhom, Slovakia.

Email: bockova@dti.sk

Received: 02 July 2021.

Revised: 04 November 2021.

Accepted: 10 November 2021.

Published: 26 November 2021.

(c) BY-NC-ND (C) 2021 Kateřina Bočková, Václav Šimek \& Michal Hanák; published by UIKTEN. This work is licensed under the Creative Commons AttributionNonCommercial-NoDerivs 4.0 License.

The article is published with Open Access at www.temjournal.com
We all started with primary education, we continued with secondary and many individuals also with tertiary education. However, this may not be a final.

There is a lifelong learning in which individuals tend to shape and develop the knowledge and skills they use or need in their jobs. It is a way to keep our professional knowledge "fit" at all times.

Why should we measure the added value of the education?

The level of education affects the gross domestic product, which is confirmed not only by the study of Münich, Protivínský [17]. The higher the level of education, the higher the GDP. Also in countries with high productivity and high growth rates, most people live at a high standard of living and there is a faster rate of average income growth. These positive impacts can be ensured by quality education, quality tools for the production of goods and services and easy availability of technologies, which includes the well-known Solow's model of economic growth. Investment in technology or in the research and education then creates such externalities that increase the efficiency [16]. Furthermore, individuals with a university degree also have a lower unemployment rate compared to the individuals with a lower level of education [12]. It is therefore important to know how good the education is and what added value it brings not only to individuals but to the society as a whole.

In this paper, we will focus on analyzing the added value of MBA studies in human capital. The MBA Master of Business Administration - is a management training program, most often attended by top managers and representatives of companies who need personal development [13].

In the Czech Republic, too many authors do not study this issue. Added value is generally addressed in e.g. [21], [5], [12], [22] or [3]. [3], however, focuses more on the effectiveness of education. Direct surveys in this area are often conducted only by the management of MBA programs to determine the specific benefits of the education they provide. However, extensive studies on this topic have been conducted abroad. E.g. Cunha, Miller in [5] are concerned with identifying the added value of higher education at Texas universities. Furthermore, the 
MBA study was directly analyzed by Fisher et al. in [8], who used Data Envelopment Analysis (DEA) methodology to evaluate programs to rank fifty US MBA programs according to their added value. However, their procedures cannot be fully used to analyze the added value under Czech conditions and available data, so they will only serve as an inspiring framework for our research.

\section{Problem Formulation and Methodology}

The aim of our research is to identify the added value of MBA studies for its graduates as bearers of human capital. We will focus primarily on their careers and career growth, changes in the amount of earnings, employment in foreign corporations, contacts gained during the study with regard to their use for business purposes and employee benefits. We will also analyze the return on investment in MBA studies.

The means to fulfil the set aim will be the use of various mathematical-statistical and comparative methods and the analysis of information, which we will then use to evaluate the data obtained on the basis of a semi-structured interview and a questionnaire survey.

The expected benefit of the research is to show, through the analyzing of the added value of the MBA management program, that education has a positive impact on the career and thus it motivates further education during working life. At the same time, the procedures used in the research can serve as a source of inspiration for further possible research in this area.

Research activities consist of two 2 parts - preresearch and research. As a part of the preliminary research, a semi-structured interview was conducted with two graduates of the analyzed MBA studies, during which we got acquainted with the situation with regard to their careers and related topics before and after the study, who motivated them to study, benefits of study for their personal development, etc. Based on the answers obtained, a questionnaire was created, which was sent via e-mail to MBA graduates at the Academy of Crisis Management and Management, Ltd. Uherské Hradiště. The expected number of respondents was 250 , however, a total of 78 respondents in different age categories took part in the research. Of the total number of respondents, 64 were men, i.e. $82 \%$ and 14 women, which is $18 \%$.

The biggest limitation of our research is that it is not possible to find a suitable control sample (individuals without an MBA studies with otherwise the same characteristics). This is because MBA study is a part of a lifelong learning and is attended by individuals in different age categories around 23-60 with different highest levels of education, years of practice, industry in which they work, etc. This problem will be partially solved by dividing of the research sample into multiple samples according to some internal factors that we compare with each other. Factors are, for example, the university from which they obtained their diploma; the sector in which they have worked or are working; gender, etc. Thus, the research finds out the added value of this study compared to the situation in which the respondents found themselves before starting it. However, it should be borne in mind that the respondents in the analyzed period (before, during and after the study) were affected by other factors that may also have played a role in the analysed variables. It is a factor of time, gaining new experience and knowledge beyond MBA studies, age, industry employment, or other social and economic factors.

The research problem is defined by research questions and partial subquestions, the answers and subsequent analysis of which will lead to the fulfilment of the set aim of the research. The questions are as follows:

1. How, from the perspective of graduates, the starting or graduating of the MBA studies affect their career with regard to:

a. A change of employer / position or career growth? How many levels do they move?

b. The amount of earnings; To what extent is it possibly changing?

c. Their employment in foreign corporations (even in the Czech Republic);

d. Who were they motivated to study MBA?

e. Contacts for new classmates acquired during the study;

f. Employee benefits provided before and after MBA graduation.

2. What is the correlation between the number of years of practice and the hierarchical position, the number of years of practice and the amount of earnings, the number of years from the MBA graduation to the present?

\section{HYPOTHESES:}

H1: MBA graduates who have more years of practice work in a higher hierarchical position than graduates with fewer years of practise.

H2: MBA graduates who have more years of practice have higher earnings than graduates with fewer years of practise.

H3: MBA graduates who have more than one year from graduation have higher earnings than graduates with fewer years from graduation. 
3. What is the payback period and rate of return on funds invested in the MBA studies? What do the non-financial outputs of the study look like?

We determine the added value of the MBA studies using the method of data comparison. Furthermore, mathematical-statistical methods are used, correlation or regression analysis, T-test, analysis of variance or chi-square is also applied to selected variables.

In most cases, the results of individual analyses are compared between respondents and according to other factors.

The added value is also related to the payback period and rate of return on investment, because the investment in it is not small, and even if graduates experience a positive impact of the study, for example immediately or immediately after graduation, the funds themselves may begin to return several years later. The rate of return on investment can be determined using the IRR (Internal Rate of Return) and ROI (Return on Investment) indicators.

The respondents are MBA graduates from the Academy of Crisis Management and Management, Ltd. Uherské Hradiště. This is managerial education and respondents most often work in managerial positions at various levels of management.

The research sample is very diverse, both in terms of age and scope of sector.

Respondents of men participated in the research the most in the age category $31-40$ years $(32.8 \%)$ and on the contrary the smallest representation of them was under the age of 30 , as well as over 56 years (7.8\%). Most women were aged 41-50 (57.1\%) and, conversely, the least were under 30 (7.1\%). None of the female respondents was older than 56 years. The low representation under the age of 30 is due to the fact that the MBA is a managerial study program and the manager (at higher levels) is not usually so young people. Moreover, in this age category, there are relatively recent university graduates who are just looking for their first job and thus do not need to study in a managerial field. On the other hand, managers in the more advanced age category are already experienced and have many years of practice. They often have nowhere to grow hierarchically, so they do not even need to expand their knowledge and look for something "new".

The highest level of education attained can play a major role in respondents' careers. Given that the condition for admission to the MBA studies is at least a bachelor's degree, there is no one among the respondents who would have a lower education. There were $6.4 \%$ of respondents with a bachelor's degree, $80.8 \%$ with a master's degree and $12.8 \%$ with a doctoral degree.

It is also important to mention the status or position of the respondents, which are factors that again play a role in their careers. Prior to the MBA studies, respondents are most often employed by one or more employers $(80.8 \%)$, or they work as selfemployed persons, executives or business owners $(17.9 \%)$. Only $1.3 \%$ of the total number were students.

The sectors in which the respondents worked / are working were grouped according to their similarity and also according to their representation in individual sectors. If only a small number of graduates worked in any of the sectors (often only one respondent), this was assigned to the group of the most similar branches.

The sectors with the largest representation of MBA graduates are engineering, construction and the automotive industry with $37.2 \%$ of respondents before the study and $35.9 \%$ at present. Furthermore, graduates most often worked and are working in IT and telecommunications $(16.7 \%$ and $15.4 \%)$, then in the group of agriculture, food industry, manufacturing industry $(12.8 \%$ before the study and today). The lowest number of respondents before starting the study was in the electricity and energy sectors, as well as in services, culture and sports (both 7.7\%). At present, representation in electricity and energy predominates by 3.9 percentage points over services, culture and sports. In total, only $11.5 \%$ of respondents currently work in a different field than before their MBA studies.

By further education we mean company courses and trainings, language courses or higher education. As many as $65.4 \%$ of respondents stated that they had participated in further education outside the MBA at that time. This is, among other influences on MBA students, an important factor that could have influenced the analyzed variables. In some analyses, where participation in further education could play a certain role, its influence on an analyzed variable is also examined.

\section{Overview of the Current State of the Issue}

The MBA, Master of Business Administration, is one of the most prestigious degree programs in the United States and in the world. It originated in the early $20^{\text {th }}$ century, when the United States began to be heavily industrialized. With the development of the technology, the Industrial Revolution initiated the need to employ individuals in various fields. Company managers were looking for employees who would be able to manage the management techniques including science and business practices better due to the large and rapid development of new companies [12].

MBA studies in the Czech Republic can be compared to Czech master's studies in economics, strategic management and management. It is a 
prestigious non-academic professional title, which is obtained after graduation by graduates working mainly in the middle and top management positions, because one of the input parameters is required for at least 2-3 years of (managerial) practice. We can therefore consider the MBA as an accelerator of a professional career. Another requirement is the completion of at least a bachelor's degree and the payment of a tuition fee [18].

This education cannot replace regular Czech master's studies. In our education system, the MBA is included in the category of lifelong learning according to Section 60 of Act No. 111/1998 Coll., On Higher Education Institutions. It is therefore not even possible to nostrify it, i.e. to recognize it as an equivalent of higher education studies awarded by the relevant faculty. On the contrary, it is possible to nostrify the full-time form of MBA study successfully obtained at a foreign university, if the content of subjects, length of study, quality of school, etc. correspond to study at the Czech faculty [13],[21].

The MBA "educates" individuals from practice, its main goal is to connect theory with this practice, often focused on the activities that students encounter on a daily basis at work. Working with such students is therefore very different from working with regular university students without practical experience. MBA students work in teams, collaborate on real case studies, solve current global problems, exchange valuable experiences from their own practice, learn from their classmates and often use the contacts gained in this way in business cooperation [9].

In 1998, the Czech Association of MBA Schools (CAMBAS) was founded. The founding members were the University of Economics in Prague (VŠE) represented by the Prague International School of Management, the Czech Technical University in

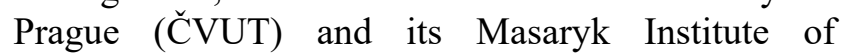
Advanced Studies, and finally the Brno University of Technology (BUT) with the Brno Business School at the Faculty of Entrepreneurship [21]. As MBA studies are not embedded in the ranks of valid university studies, they are not required to be accredited. However, CAMBAS provides this accreditation to its interested members to meet certain international standards. However, the fact that an MBA provider is a member of this association does not mean that it is automatically accredited. Many of them have their MBA programs accredited by foreign agencies in the country in which they have a partner university. Accreditation can generally increase the value of a program in the eyes of some applicants, as it should provide it with the required level and quality.

As already mentioned, MBA studies are a paid type of education in the Czech Republic, and in addition to the tuition fee, there are several conditions for admission to study. Thus, both exclusionability and rivalry are obvious. Some providers operate it under the auspices of a public institution, such as public universities on a non-profit basis. However, there are purely private providers who aim to make a profit. For these reasons, MBA studies are closest to a private estate.

We can look at this type of education from another point of view. MBA studies are primarily intended for managers at various levels of management, most often at the middle or top level. The MBA studies providers choose their students, and not everyone can afford such an education due to considerable tuition fees. We can talk about the MBA study as a luxury farm, because with increasing income we can afford to consume it.

MBA studies have been becoming a hot topic in the Czech Republic in recent years. With this, surveys in this area are being developed to find out what competitive advantages it provides to MBA graduates over others. In the following section, we present three relevant surveys.

Research realised by Tucker and Scully in 2020 [23] found that the salary of MBA degree holders had increased by $15 \%$ a year after graduating, up to $40 \%$ five years after graduation. As a specific example, the survey creators state "a typical middleranking manager who applied for an MBA in 2004, so his salary at the start of the course was CZK 35,000 . A year after graduation it was already CZK 46000 and today he earns CZK 63 000" [23]. However, it is clear that graduating the MBA studies does not automatically provide this financial procedure for its participants. The MBA studies move them professionally forward, with which the increase in income is logically connected.

Furthermore, a research published in [20] found that $92 \%$ of MBA graduates moved one or more positions in the corporate hierarchy due to their MBA degree, $90 \%$ of graduates obtained a better job within 1 year after graduation, to $45 \%$ of them the tuition fee cost returned within 1 year, or to $75 \%$ of MBA graduates the studies helped to increase the financial reward by $10-30 \%$. However, nowhere in the results was it stated whether other factors affecting graduates other than MBA studies were also analyzed.

There are many surveys from individual MBA studies providers and most of them report very similar results. In general, MBA studies often help not only to improve a job position, but also to increase the financial rewards and to become more attractive to employers. However, these surveys are usually presented only very briefly without more specific results. 
The added value of education can be understood as the progression between two decisive periods, i.e. we compare the condition of an individual before and after graduation a study / educational event. At all levels of education, in addition to increasing knowledge and skills, there is the creation of sociocultural structures that shape the overall cultural and social level of the state. Learning outcomes represent the immediate changes on the part of learners and we associate them with a higher degree of correlation with teaching and with the possibility to measure it immediately. On the other hand, the outcomes of the education can be determined only with a greater distance from one's own education and the actual correlation to education in a given institution is not clearly definable. In addition, the formulation of the target status of graduates differs at different levels of education. One will be for primary school pupils and another for university students [21].

In the case of lifelong learning, and therefore MBA studies, which focus on deepening the knowledge, skills and abilities associated with the practice, this target state of the graduate will be such as:

- be loyal to the employer;

- be professionally prepared;

- be able to expand this professional basis and use it in practice and in personal life;

- have the competence to lead behaviour and leadership, the competence to communicate and cooperate, to solve problems and creativity, to accept responsibility;

- have the ability to argue and evaluate;

- be willing and able to learn;

- be proactive;

- be ready for teamwork, etc. [2].

[5] defines added value from the point of view of an educational institution as the contribution of a school or higher education institution to the student's progress towards the set educational goals over time.

$[7$, p. 66] in their study deal with finding out the added value of higher education at the universities in Texas. "This university study provides knowledge and skills that increase students' economic activity and thus earnings, and higher earnings in turn increase the budget for consumption and leisure."

Non-monetary benefits also include, for example, a greater choice of job opportunities, a better ability to decide on important events in life, such as marriage, health, parenthood or an increased sense of general happiness [19].

Universities also, through their graduates, produce the positive externalities that affect society as a whole. These externalities take the form of increasing knowledge and thus have a positive effect on companies. External effects work here by exchanging ideas, imitating or learning something we do directly
[1]. Well-informed citizens also contribute more to the public good, which improves the functioning of the society through actions such as public choice, although education could lead to less fluctuation, as an educated individual is very unlikely to have a voice influencing current politics [6].

For educational programs, it is possible to monitor the added value from two perspectives. From the perspective of the graduate as an employee and from the perspective of the employer [14].

When we focus on MBA studies, the employer often finances or partially subsidizes its employees with a vision of benefits for the company in the form of lower employee fluctuation, of a better qualified, capable and motivated employee who has this added value for the company after graduation compared to his original situation. The employee contributes to achieving the better results for the entire company, to strengthening its position in the market, higher profits or greater expertise. It can achieve this through skills acquired in education - quality leadership and rewarding people, knowledge of effective project management, better orientation in possible risks for the company, greater knowledge of foreign languages, etc. [4].

On the other hand, we can observe the added value of education for the individual in the position of an employee. This means employment on the Czech or foreign labour market, job position and the possibility of career growth, the amount of earnings, other employee benefits that can serve as an alternative to earnings (with career growth, e.g. the possibility to use a company car for personal use, more days off, life insurance contribution, etc.), time needed to get a (dream) job, time needed to get a higher job position. A very important factor in lifelong learning is gaining of the valuable contacts with the schoolmates, which broaden the horizons and opportunities for individuals to work and do their own business [11].

All the mentioned aspects, which the individual acquires thanks to the MBA studies, affect the whole economy and thus the whole society. As mentioned, educated people have higher labour productivity, they create the positive externalities, contribute to the public good, etc. It is not only the employer and the graduate himself as an employee who are affected by the added value of education.

When modelling the added value of education, it is always necessary to compare two time sections in which the results are determined. [2, p. 15] defines these models as follows: "Value-added models measure the school's contribution to the pupil's progress towards predetermined school educational goals. The contribution is a value-adjusted value from other factors that also contribute to the pupil's learning progress." In order for modelling to be 
feasible, it is necessary to select data that can be identified and that affect the learning issues and the influencing factors.

Value-added models include statistical models. In order to be used in practice, we consciously simplify the real quantities and processes. It is necessary to keep in mind that during the life of people, they are also affected by other influences, which may be stronger than the action of the educational institution itself and may often be more important for work and personal life. However, it is not at all easy to determine the adjusted contribution of an educational institution to their learning outcomes [21].

We measure the added value mainly by assessing the results in two time sections. We call this approach a cross-sectional evaluation, where we obtain data at the beginning and the end of the study, but not for the same students. These students must have the same certain characteristics, in particular the proximity of their initial qualifications and age. It is therefore assumed that the characteristics of current students entering education are similar to those who are just graduating. Here, therefore, it is difficult to capture any changes that have occurred during the process, such as changing admission requirements [21].

The second approach to measure the added value is the longitudinal evaluation, where learning outcomes are measured in the same group of students. Its results may be influenced by other influences outside the educational institution, which could be overcome by participating in the survey of a group of individuals with similar characteristics, but who are not further educated in the institution at the level at which we survey [21].

In the case of the analyzed MBA studies in the Czech Republic, it is not possible to meet the condition of a sample of students of the same age and initial education. Although the admission procedure stipulates the basic conditions for admission to study, the fact that MBA studies in the Czech Republic is a part of lifelong learning is attended by individuals of various ages and education.

For both types of evaluation mentioned above, we usually mean the evaluation using comparative tests (such as SCIO, PISA, GMAT), which assess critical and analytical thinking, problem solving, mathematical knowledge, communication skills, knowledge in business and management, etc.

The test results clearly show any progress between periods based on the score obtained. Some of them are already identifiable with the case of MBA studies. Some institutions in the Czech Republic (for example, FP BUT in Brno) require as one of the admission parameters to the study the fulfilment of GMAT and TOEFL tests, which ensure a certain quality of the program. Based on their evaluation, it is therefore possible to obtain certain input parameters with which applicants enter the program. In this case, however, the limitation is that applicants for study at FP BUT in Brno take tests only before the start of the study, but not after graduation. Thus, we do not have any output parameter of this type with which the result of GMAT and TOEFL tests could be compared.

In the United States, several studies have been conducted, the purpose and result of which was to rank fifty MBA programs at various universities according to their quality, by determining the added value of each program examined. [8] used the DEA methodology to evaluate programs, where they monitored students' learning outcomes and cost elements (tuition, accommodation costs, time needed to complete their studies) and then measured the performance of students in the labour market as outputs. Students' learning outcomes were measured using the average score from the GMAT test and the average of grades, the so-called GPA. They set the average initial salaries and bonuses, the employment rate at the end of studies and 3 months after graduation. In order to achieve the best possible results in the measurement, the second measurement also included parameters such as tuition, accommodation costs, program length and other additional costs. Using these inputs and outputs, all MBA programs provided by different universities were compared using computer software that implemented the DEA model using a linear programming technique.

There are other possible ways in which the added value of education can be ascertained. [5] in their value-added study at 30 universities in Texas used the rich supply of administrative data on individuals provided by the state of Texas. They wanted to avoid the traditional method of determining added value in the form of the results of various types of tests that students write before and after their studies. Instead, they compared the degree of perseverance and the resulting degree of completion of the program and the earnings after graduation. However, a limitation of the use of these data is that they can be observed in an individual only once (perseverance and completion) or only after graduation (earning). Thus, the estimation of individual differentiation could not be used. The above data comes from various administrative sources such as the Texas Higher Education Coordinating Board (THECB), which collects information on individuals applying to a college in Texas, whether a student has been accepted, and at which university, hours of study, and credits for each semester and whether or not the individual has completed the study. These data were supplemented by other sources. The individual variables were subsequently unified and the authors 
performed a regression and correlation analysis, on the basis of which they were able to compare the dependence between the variables and then to rank the universities according to their greatest added value, which they provide to their students.

The added value of education is very difficult to measure in any way. Therefore, we could use offmarket methods of valuing goods and services that are used where there is no direct financial expression of their value. In other words, the value of these goods and services cannot be determined simply by how much we pay for them [15].

There are a large number of non-market valuation methods, but in the context of education we will list only the following two, with which it would be possible to work further in our work.

1. The hedonic method analyses how different characteristics of goods on the market can affect their price. It is most often applied in connection with environmental externalities and is used in the real estate market. However, we can also use it in the labour market, where by examining the wage differential between jobs with different levels of risk, we estimate the willingness to accept compensation for the increased risk of injury or death that is included in wages [20]. The wage differential expresses the quality of the work environment, such as work safety, social prestige, stress, entertainment, work environment culture. These non-monetary characteristics are a source of compensatory pay gaps [10]. In connection with education, it is possible to start from this wage differential, which is closely linked to the hedonic valuation method. When considering graduates of a certain education, the wage differential depends on the level of education attained, when we compare the characteristics of graduates in connection with their employment in the labour market before and after completing their studies / educational events. We thus express its added value in the form of higher social prestige, better paid jobs and other benefits.

2. When valuing the added value of education, it is also possible to be inspired by methods based on a non-preferential (expert) approach, specifically, for example, a method based on "dose-response data". This is again most often used in the valuation of environmental changes due to pollution. The relationship between environmental damage and its impact on the production is calculated on the basis of the response function [24]. In the case of education, this method can be used not in this negative direction, but on the contrary in a positive way. The effect of education can be considered to increase and strengthen the knowledge, skills and abilities of graduates. The result can be a better job in the labour market, higher job positions, better remuneration for work, benefits for the company in the form of better work, increased labour productivity, profitability, etc.

We present non-market valuation methods only as a topic for a different view of the researched issue. However, they are not used in any way in our research.

\section{Results and Discussion}

The added value of MBA studies has been examined with regard to the careers of graduates and possible career changes. The added value was considered to be fulfilled expectations, career growth in connection with the number of years of practice and the originator of motivation to study, as well as the position with regard to the number of years from graduation.

Another analyzed parameter was the gross monthly earnings and its change, again by monitoring the number of years of practice before study, the scope branch, the age, further education, origin of motivation for MBA study and the number of years from graduation. Earnings was also examined in connection with the origin of the employer (Czech, Slovak $\mathrm{x}$ foreign) or with the sources of study funding (own, corporate, combined).

The research was further focused on the ratio of graduates employed in Czech / Slovak companies in correlation to foreign corporations and on the frequency of foreign business trips before and after graduation. An important added value is, in addition to the mentioned factors, the contacts gained, which helped more than one third of the respondents to establish business relationships. Finally, employee benefits, whether financial or non-financial, were also considered as added value.

When calculating the payback period of funds invested in the MBA studies, inputs were taken into account in the form of tuition, opportunity costs, travel and accommodation expenses. The output was determined to be an increase in average gross monthly earnings. The payback period of the funds invested in the study itself was added to the time when the respondents' increase in earnings occurred.

The internal rate of return (IRR) indicator and the ROI investment indicator were used to calculate the rate of return. Here we have included only respondents who attach a certain share to the MBA studies to the increase in earnings. First, the IRR was calculated, where cash flow makes up the entire earnings, including the amount of its increase. The investment returned in this way in the first year. However, this method of calculation has no relevant informative value, because students would receive 
earnings anyway. The second IRR calculation was therefore performed only with cash flow containing only the amount of increase in earnings. It turned out that after five years the NPV and IRR are still negative, only after eight years the investment was returned in a small part. The same procedure was used for the ROI indicator and the results were very similar.

Respondents most often worked before MBA studies in the position of top management (43.4\%), with an average practise length of 10 years. At the same time, a significant correlation between years of practice and hierarchical position was demonstrated among MBA graduates.

It was found that most respondents changed employers during or after MBA studies (32\%) and $13 \%$ were promoted. However, for all $28 \%$ of respondents there was no change, incl. changes in the amount of earnings.

When asked whether the respondents think that the changes were caused by the MBA studies, 51.9\% answered positively (whether the MBA studies caused them to a greater or lesser extent) and the remaining $48.1 \%$ do not attach much or no weight to the studies.

Career growth was recorded by only $30.8 \%$ of the total number of respondents, which may be affected by the short time since the MBA studies graduation. Overall, many respondents in top management worked before the study and thus have no further place to grow.

Graduates most often moved by 1 hierarchical position, already during their studies $(33.3 \%)$. Some moved by 2 positions within 1 year from the graduation $(12.5 \%)$, or even by 3 positions already during their studies $(8.3 \%)$.

At the same time, it was found that participation in further education before or during the MBA has nothing to do with career growth.

Regarding the current hierarchical position (June 2020), there was a decrease in the number of respondents in the position of ordinary worker, lowest and middle management compared to the situation before the MBA studies, and, conversely, an increase in top management positions. At present (according to data from July 2020) $50.9 \%$ of respondents are at this level, with an average of 7.3 years elapsed since the MBA studies graduation.

It turned out that even before the MBA studies, most respondents $(41.5 \%)$ received an average gross monthly earnings of more than CZK 80,000, which corresponds to their large number in top management positions. These respondents had an average of 12.4 years of practise. However, no significant dependence was demonstrated between the number of years of practise and the amount of earnings.
The highest earnings before the MBA studies were clearly recorded in the IT and telecommunications sector, averaging CZK 85846 per month for all respondents. On the contrary, the lowest was in the field of electrical engineering, energy CZK 44,833, in which, however, only a small number of respondents worked, which could affect the overall result. A correlation between age and earnings was also analyzed before the MBA studies which showed a moderate and statistically significant dependence.

Overall, an increase in earnings was recorded by $53.8 \%$ of respondents, i.e. more than half. It most often occurred during the studies $(30.6 \%$ of individuals), by $26.1 \%$ compared to the earnings before the studies. However, only $1 / 3$ of them think that the MBA studies really helped.

The highest increase occurred up to 5 years after graduation by $33.8 \%$, but only in $8.3 \%$ of respondents, and everyone thinks that this increase was really helped by MBA studies graduation. Overall, it was shown that the higher the increase in earnings, the lower it was before the studies and thus had much more space to grow. At the same time, the longer the time from the studies graduation, the more respondents attribute the MBA studies.

The amount of earnings and its increase is influenced by various factors, and using regression analysis, it was found that age was the most important. Neither the number of years of practice nor the number of years from the MBA studies graduation has anything to do with the increase in earnings.

The highest increase in earnings was recorded in the total analyzed sample in the electricity and energy sector, where respondents had the lowest earnings before the studies (increase by $30.7 \%$ ) and in services, culture and sports (by $22.1 \%$ compared to the average earnings before the studies).

A total of $65.4 \%$ of respondents participated in further education outside the MBA during the MBA studies. There was also a higher increase in earnings than in individuals who were not educated elsewhere. Overall, it was an increase of $9.4 \%$ (nonparticipation) vs. $16.4 \%$ (participation). The T-test also confirmed a certain correlation between these two variables.

The decrease in earnings occurred in $5.7 \%$ of respondents. In the first case by $25 \%$ of its original amount in the field of healthcare, in the second it cannot be determined, because the respondent in both monitored time periods were in the category of earnings over CZK 80,000, but it was in the IT and telecommunications sector. In the latter case, the respondent's earnings decreased by $47 \%$, which was in the area of services.

Previous analyses show that currently most individuals are in the category of earnings over CZK 
80,000. Respondents have an average of 7.5 years from the MBA studies graduation. It is again interesting that there is only a negligible correlation between the number of years from graduation and the amount of earnings.

According to the performed analyses, the origin of the employer significantly affects the amount of earnings. Graduates working in companies with a foreign owner earn significantly more than graduates working in companies with a Czech / Slovak owner, both before and after the MBA studies. Before the studies, respondents working for foreign employers had $25.3 \%$ higher earnings than those who worked for a Czech / Slovak company, currently (July 2020) the difference is $25.7 \%$.

The financing of studies by the employer $(48.7 \%$ of the total number of respondents) does not significantly affect their subsequent change in earnings. The largest increase occurred in individuals paid for by the employer (on average by $16.2 \%$ compared to the average gross monthly earnings before the studies), but only by $0.1 \mathrm{pp}$ more than in the case of private financing.

Analyses have shown that the MBA studies graduation, which helps open the door to a foreign labour market, has no effect on the transfer of labour to foreign corporations. On the contrary, before the MBA studies, $51.3 \%$ of respondents worked in foreign companies, i.e. slightly over half, and currently, according to data from July 2020, it is slightly less, namely $46.6 \%$. There was also a decrease in business trips abroad from $62.8 \%$ of respondents before studying to the current $59.7 \%$.

According to the results of the analysis, the cause of motivation (own, employer, others) did not have a special effect on whether individuals changed employers, positions or were promoted.

The largest increase in earnings occurred in those individuals who studied MBA on the basis of selfmotivation, by an average of $14.5 \%$ of gross monthly earnings before studies, while the smallest in the case of the origin of motivation by the employer, by $11.1 \%$. So it's not a big difference. In the given sample of respondents, it is also very difficult to assess, because only a few of them were motivated to study by the employer and the results can be significantly skewed.

Thanks to the newly acquired contacts within the MBA studies, $38.5 \%$ of respondents established business cooperation. In this case, they most often cooperate once a year $(26.7 \%)$, or even several times a month (20\%). Contacts are considered an important part of the studies, because without it, business cooperation would probably not have arisen and also serve for possible future use.

At present, individuals generally enjoy more employee benefits than before the studies (found in
$56.6 \%$ of individuals). From a general point of view, according to individual answers, the use of both financial and non-financial benefits increased compared to the situation before the studies. When focusing on specific benefits, the use of the meal allowance decreased the most (by 13 percentage points), while the provision of regular remuneration (by 5.6 percentage points) or the holiday allowance (by 5.1 percentage points) increased the most.

For non-financial benefits, the largest decrease was recorded in the use of mobile phones for private purposes (by 5 percentage points) and the largest increase in the possibility of home office (by 16.2 percentage points) or the use of the corporate tariff (by 11 percentage points).

\section{Hypothesis Testing}

H1: MBA graduates who have more years of practise work in a higher hierarchical position than graduates with fewer years of practise.

When testing H1, thanks to correlation analysis and Spearman's coefficient, it was shown that MBA graduates have a significant correlation between the number of years of practice and the hierarchical position. So we do not reject $\mathrm{H1}$.

H2: MBA graduates who have more years of practise have higher earnings than graduates with fewer years of practise.

The hypothesis was tested using Pearson's correlation coefficient, which showed that the MBA studies respondents do not have a large correlation between the number of years of practice and the amount of earnings before the studies. The correlation was not confirmed either during its testing with the amount of earnings after its increase in close time to the MBA studies, nor with the earnings at present. $\mathrm{H} 2$ cannot therefore be accepted.

This is an interesting result also considering that the correlation between the number of years of practise and career growth has been confirmed. However, age was found to correlate with pre-study earnings moderately and with significant significance. However, the correlation with age has not been confirmed for current earnings. It is therefore possible that the age played a role until before the studies, but currently other influences have an effect on earnings.

H3: MBA graduates who have more than one year from graduation have higher earnings than graduates with fewer years from graduation.

The hypothesis was tested again using Pearson's correlation coefficient. It showed only a very small correlation between the two given variables, and moreover with insignificant statistical significance. Therefore, the hypothesis cannot be accepted. 


\section{Payback Period and Rate of Return on Investment in MBA Studies}

The average payback period for an MBA studies is 2.6 years. Not surprisingly, the investment in MBA studies returned the fastest to those whose earnings themselves had already increased during the studies, which is the case for students of the Academy of Crisis Management and Management, Ltd. up to 2.4 years. This is the shortest possible payback period. On the contrary, it was the longest for those whose earnings increased up to five years from the graduation, which is 7.6 years.

The rate of return was calculated using the internal rate of return (IRR) and the ROI indicator - Return on Investment, and only for individuals who think that the increase in earnings is due entirely or to some extent thanks to the MBA studies. When calculating the IRR, where the cash flow makes up the entire amount of earnings, including the amount of its increase, the investment will return from $154 \%$. However, this distorts the whole result, because individuals would receive earnings even without an MBA studies, it would only be lower.

Therefore, the second method of calculating the IRR considered only the amount of increase in earnings for cash flow. It turned out that five years from graduation, the investment has not yet returned, the IRR was $-15.3 \%$. Only after eight years did the investment return for a small part, IRR $=2 \%$.

The ROI was calculated in the same way and the results were similar. After five years, the ROI was $50.6 \%$. Only eight years from graduation, ROI reaches positive values, $12.3 \%$.

Most individuals $(83.3 \%)$ recorded a better orientation in the taught areas. Furthermore, communication and presentation skills were developed in $61.5 \%$ of cases, and knowledge of the English language improved in almost half. About 1/3 of the respondents improved their ability to manage the financial situation in the company, human resources and the ability to apply the acquired theoretical knowledge in the performance of employment. About $1 / 4$ graduates noted improvements in project management skills and new knowledge of how the market works. None of the named non-financial benefits occurred in $6.4 \%$.

\section{Theory Versus Practise}

The importance of education and its impact and the fact that high productivity and its high growth rate ensures a higher standard of living and a faster growth rate of the average earnings were discussed above. This is then reflected in higher consumption (people spend more) and GDP growth, which means that education has a positive impact not only on individuals but on the whole economy and society. In the case of MBA studies, this is especially true because it is attended by managers in high positions, most often at the level of top management and with relatively high earnings. MBA studies contribute to faster and greater growth both in the career ladder and in earnings, which was found from previous surveys listed in subchapter 3 and from our research. In addition, when financing studies from the employer's resources, individuals often commit to the employer in some way, either to work for a certain period of time or to perform certain tasks, which helps reduce the staff fluctuation and maintains stability in the company.

The added value of the MBA studies was determined in the research by longitudinal evaluation, i.e. by measuring the educational results of the same group of students in two time sections. A large proportion of respondents were found to have positive results in correlation with their careers. So it may seem that studying really has a price. The results of the CEMI survey also show significant positive impacts. However, it is always necessary to take into account that these are changes that may not only be affected by MBA studies, because at the same time students are affected by other factors such as age, gender, years of practise, experience, company with which they are employed, further education, other social and economic factors, etc. This applies to all types of education and it is therefore very difficult to measure its real added value. In the research, we therefore examined various variables in correlation to other factors that may have influenced. For some, this theory has really manifested itself (e.g. age, participation in further education, the origin of the employer, etc.).

\section{Suggestion for Further Research}

Fisher et al., in [8] used inputs in the form of GMAT test results and GPA grade averages (among others) in their study of the added value of MBA studies in the United States. As already mentioned, students at the Academy of Crisis Management and Management, Ltd. during the entrance test, they pass the GMAT test, which could therefore be used to determine the added value. However, the concept of research would have to be different - not so anonymous. Specific individuals would have to be selected and then asked the same questions as in the research, but not anonymously. These would then be assigned their GMAT test results and incorporated into the value-added measurements. The risk is that individuals may not want to cooperate due to inquiries about sensitive data (age, earnings, etc.) or would not provide completely true information.

However, this tip may be a topic for further research into the added value of the MBA studies.

An examination of the online MBA program and its added value compared to the full-time study could also bring interesting results. 


\section{Conclusions}

The basic element of today and current working life is an education. This is clearly evidenced by statistics on the development of the highest level of education attained, which show a constant increase in the number of individuals with a university degree. It is also proven that the higher, and especially better, education an individual achieves, the higher the standard of living he ensures not only for himself but also for his surroundings. It helps to increase the productivity, its faster growth rate and thus higher GDP. When we put together several such individuals, the results of their work will begin to affect the whole economy and society. Furthermore, a higher unemployment rate was also demonstrated for university-educated individuals than for individuals with a secondary education, which proves that the educated individuals are more attractive to employers. However, the process of education does not end for many in higher education, and in the course of working life there will be a need to deepen the knowledge acquired so far. At that moment, lifelong learning comes into play, which is focused on the practical application of acquired knowledge and skills in the field of activity of an individual. However, it is very difficult to capture the real added value of any educational event, because the individual is affected by a large number of environmental influences, which also affect the output of education.

The goal of our research was to determine the added value of the MBA (Master of Business Administration) studies for its graduates, specifically the MBA studies at the Academy of Crisis Management and Management, Ltd. in Uherské Hradiště, while this added value was analyzed with regard to the careers of graduates and the changes that occurred in the near future from their graduation. At the same time, selected factors and their possible influence on the changes were examined as well. These include, for example, age, number of years of practice, number of years from MBA studies graduation, the origin of motivation to study (employer, own, family), or participation in further education.

The results of the research showed that the respondents most often expected personal development from the MBA studies, which was also fulfilled in almost all of them. The situation was similar in anticipation of the use of acquired knowledge and skills in the performance of employment. Surprisingly, however, only half of the respondents who expected their person to be more attractive to a potential employer did so. In doing so, the MBA studies are considered to be a proponent of attractiveness for employers. However, this is the subjective opinion of the respondents.

Furthermore, the results showed that the respondents already most often worked in top management positions before the MBA studies. Less than $1 / 3$ of the respondents experienced career growth, most often by one position during their studies. In terms of earnings, an increase was recorded in 53.8\% within 5 years from graduation, by $33.8 \%$ compared to its original amount before the studies (in $8.3 \%$ of individuals). On the contrary, $5.7 \%$ of respondents reduced their earnings.

The results also showed that the higher the increase, the lower were the earnings before the studies and therefore had more space for growth. Interestingly, there is no significant correlation between the number of years of practice and the amount of earnings of graduates, as well as between the amount of earnings and the number of years from the MBA graduation.

MBA studies are generally considered to be a means that, due to its international reach, facilitates entry into the foreign labour market. However, this was by respondents from the Academy of Crisis Management and Management, Ltd. not proved. On the contrary, the number of respondents employed in foreign companies (either directly abroad or in the Czech Republic) decreased by $4.7 \mathrm{pp}$ after the MBA studies graduation.

Furthermore, the payback period and the rate of return on investment in the study was determined, where it was important to separate financial and nonfinancial outputs. The rate of return was determined using IRR and ROI indicators, which determined that the increase in earnings occurred on average 2.5 years from the MBA studies graduation. The IRR for 8 years was $2 \%$. ROI indicator then $12.3 \%$. This is a relatively long time for such low values, but it can vary from individual to individual according to individual changes.

However, education mainly produces personality development, which cannot be quantified in any way. Among other things, it was found that the study benefited most from the development of knowledge in the areas taught, the development of communication and presentation skills was noted, and almost half of the respondents improved their English. The use of contacts for business purposes is also very much associated with the MBA studies, and in more than $1 / 3$ of the respondents this interaction took place or is still ongoing.

In the use (provision) of employee benefits when comparing the situation before the study and at present (according to data from July 2020) the largest decrease was recorded in the meal allowance (by 13 percentage points), but at the same time it is still the most used benefit. The same can be said for a mobile 
phone provided for private purposes. On the contrary, the largest increase was recorded for the option of home office (by $16.2 \mathrm{pp}$ ) or corporate tariff (by $11 \mathrm{pp}$ ), which probably compensates for the decrease in the use of the business telephone for private purposes.

From the above research results, it is clear that the benefits of MBA studies at the Academy of Crisis Management and Management, Ltd. is positive in all respects. Even respondents who saw a negative shift in some areas saw a positive shift in other areas. The presented results can therefore be not only a motivation for individuals thinking directly about the possibility of MBA studies, but also a benefit for further research conducted in the field of determining the added value of education. In the future, it is possible to focus on analysing of the added value of MBA studies with its graduates and compare the results with individuals without MBA studies. Another option is to ask employers of graduates directly and examine its impact on the company, which would be significantly more difficult than the way in which the research was carried out in this paper. Finding out the added value of an online MBA program in comparison with the full-time form of this type of study can also be interesting.

\section{Acknowledgment}

The submitted paper was prepared within the analytical work of the VEGA 1/0021/21 project.

\section{References}

[1]. Acemoglu, D., \& Angrist, J. (2000). How large are human-capital externalities? Evidence from compulsory schooling laws. NBER macroeconomics annual, 15, 9-59.

[2]. Yehuda, B., \& Anne, L. (2001). The added value of MBA studies-graduates' perceptions. Personnel Review, 30(5), 589-602.

[3]. Benčo, J., \& Vaceková, G. (2013). The Present Economic Model and Possible Alternatives. Ekonomika A Spoločnost', 117.

[4]. Chen, C. C., \& Jones, K. T. (2007). Blended learning vs. traditional classroom settings: Assessing effectiveness and student perceptions in an MBA accounting course. Journal of educators online, 4(1), $\mathrm{n} 1$.

[5]. Cunha, J. M., \& Miller, T. (2014). Measuring valueadded in higher education: Possibilities and limitations in the use of administrative data. Economics of Education Review, 42, 64-77.

[6]. Dee, T. S. (2004). Are there civic returns to education?. Journal of public economics, 88(9-10), 1697-1720.

[7]. Dvořáčková, J. (2015). „Knowledge is power “: Studium MBA v perspektivě Bourdieuho teorie kapitálů. Pedagogická orientace, 25(1).
[8]. Fisher, D. M., Kiang, M., \& Fisher, S. A. (2007). A value-added approach to selecting the best master of business administration (MBA) program. Journal of Education for Business, 83(2), 72-76.

[9]. Gedeon, S. A. (2014). Application of best practices in university entrepreneurship education: Designing a new MBA program. European Journal of Training and Development, 38(3), 231-253.

[10]. Hamidullah, M. F., Riccucci, N. M., \& Lee, I. P. (2021). Citizens' perceptions of closing the gender pay gap: an experimental study. Public Management Review, 23(7), 1032-1055.

[11]. Hart, C., Plemmons, T., Stulz, K., \& Vroman, M. (2017). Auditing Communication Effectiveness in Higher Education: A Team-Based Study by MBA Students. Contemporary Issues in Education Research, 10(2), 137-158.

[12]. Herrington, J. D. (2010). MBA: past, present and future. Academy of Educational Leadership Journal, 14(1), 63.

[13]. Kerkovsky, M., Janicek, L., \& Drdla, M. (2002). MBA studies in the Czech Republic. Journal of Teaching in International Business, 13(3-4), 133-156.

[14]. Kretovics, M. A. (1999). Assessing the MBA: what do our students learn?. Journal of Management Development.

[15]. Loomis, S., \& Rodriguez, J. (2009). Institutional change and higher education. Higher Education, 58(4), 475-489.

[16]. Mankiw, N. G. (2014). Principles of economics. Cengage Learning.

[17]. Münich, D.; Protivínský, T. (2013). Dopad vzdělanosti na hospodářský růst: ve světle nových výsledků PISA 2012. Praha: IDEA.

[18]. Novak, V., Vokoun, M., Stellner, F., \& Vochozka, M. (2016). Institutional analysis of the contemporary regional labour market in the Czech Republic. $E+M$ Ekonomie a Management, 19(3), 4-20.

[19]. Oreopoulos, P., \& Salvanes, K. G. (2011). Priceless: The nonpecuniary benefits of schooling. Journal of Economic perspectives, 25(1), 159-84.

[20]. Ramirez, A., Himang, C., Selerio, E., Manalastas, R., Himang, M., Giango, W., \& Ocampo, L. (2020). Exploring the Hedonic and Eudaimonic Motivations of Teachers for Pursuing Graduate Studies. The AsiaPacific Education Researcher, 1-18.

[21]. Ryška, R. (2009). Evaluace a pridaná hodnota ve vzdělávání. Univerzita Karlova v Praze, Pedagogická fakulta.

[22]. Simpson, R., Sturges, J., Woods, A., \& Altman, Y. (2005). Gender, age, and the MBA: An analysis of extrinsic and intrinsic career benefits. Journal of Management Education, 29(2), 218-247.

[23]. Tucker, B. P., \& Scully, G. (2020). Fun while it lasted: Executive MBA student perceptions of the value of academic research. Accounting Education, 29(3), 263-290.

[24]. Volden, G. H. (2019). Assessing public projects' value for money: An empirical study of the usefulness of cost-benefit analyses in decisionmaking. International Journal of Project Management, 37(4), 549-564. 